\title{
Novos registros arqueobotânicos sobre o uso de frutos na dieta alimentar sambaquiana
}

\author{
Gustavo Borba de Oliveira* \\ João Carlos Ferreira de Melo Júnior * *
}

OLIVEIRA, G.B.; MELO JÚNIOR, J.C.F. Novos registros arqueobotânicos sobre o uso de frutos na dieta alimentar sambaquiana. R. Museu Arq. Etn. 34: 174-186, 2020.

Resumo: Inúmeros são os relatos da presença de carporrestos carbonizados em sambaquis brasileiros, mas com imprecisões no reconhecimento das espécies associadas, resultando em lacuna sobre a dieta alimentar dos sambaquianos. Este estudo identificou taxonomicamente os macrovestígios do tipo fruto carbonizado de forma a ampliar os conhecimentos sobre a dieta alimentar sambaquiana. O material arqueológico analisado é proveniente do sítio Cubatão I localizado no município de Joinville/SC e pertence ao acervo do Museu de Sambaqui de Joinville. A identificação das espécies vegetais seguiu a análise morfotipológica e, posteriormente, a comparação em coleção carpológica de referência pertencente ao Laboratório de Morfologia e Ecologia Vegetal da Universidade da Região de Joinville. Amostras de frutos maduros de palmeiras foram coletadas para a determinação do seu teor nutricional. Foram analisados 905 macrovestígios vegetais tipificados como carporrestos carbonizados, com maior prevalência na camada estratigráfica de 2,03-2,08 $\mathrm{m}$ de profundidade. Foram identificadas três espécies de frutos/sementes pertencentes a duas famílias botânicas: palmito juçara - Euterpe edulis -, jerivá Syagrus romanzoffiana (Arecaceae) - e guaraparim - Vantanea compacta (Humiriaceae). As identificações realizadas ampliam o espectro de recursos florestais utilizados pelos sambaquianos no litoral de Santa Catarina, seu conhecimento sobre as espécies vegetais e o entendimento sobre a dieta alimentar de populações pretéritas.

Palavras-chave: Patrimônio cultural; arqueobotânica; antracologia; carpologia; sambaquis.

\section{Introdução}

$$
\begin{aligned}
& \text { onsiderada uma disciplina com } \\
& \text { pouco mais de duas décadas }
\end{aligned}
$$

\footnotetext{
* Bacharel em Ciências Biológicas, Universidade da Região de Joinville. <gustavo.borba.oliveira@gmail.com>

** Pós-doutorado em Botânica pela Escola Nacional de

Botânica Tropical, do Instituto de Pesquisas Jardim Botânico

do Rio de Janeiro. Docente do Programa de Pós-Graduação em Patrimônio Cultural e Sociedade. Coordenador do Laboratório de Morfologia e Ecologia Vegetal da Universidade da Região de Joinville. <joao.melo@univille.br>
}

de estudos no Brasil, a arqueobotânica, ou paleoetnobotânica, vem se firmando não apenas enquanto técnica auxiliar da arqueologia (Scheel-Ybert 2003). Esta área de estudos está fortemente ligada à tentativa de compreender o comportamento de populações passadas e a sua relação com o meio ambiente (Scheel-Ybert 2003). Revela também como tais populações se apropriavam e aplicavam diferentes usos aos recursos naturais disponíveis (Ceccantini \& Gussella 2001). 
Ganha destaque dentro da arqueobotânica a análise de carvões (madeira carbonizada), conhecida como antracologia, não apenas por sua fácil aplicabilidade, como pela diversidade de informações que pode ser obtida a partir de seu material de estudo (Scheel-Ybert 2003). Pode-se dizer que a antracologia é uma subdisciplina da arqueobotânica que estuda os macrovestígios vegetais carbonizados (carvões) provenientes de contextos arqueológicos e que fornece informações sobre o ambiente $\mathrm{e}$ as atividades cotidianas das populações do passado (Chabal 1997). Além disto, a antracologia pode trazer dados paleoetnológicos que auxiliam na compreensão da utilização dos recursos vegetais por estas populações (Chabal 1997; Chabal et al. 1999; Figueiral \& Mosbrugger 2000; Sheel-Ybert 1998, 2004b).

A existência de carvões vegetais oriundos de frutos comestiveis na matriz arqueológica é uma importante fonte de informações sobre a dieta alimentar de populações pretéritas (Schell-Ybert 2004a). Apesar do estudo destes vestígios estar muito mais atrelado ao campo da arqueobotânica do que ao da própria antracologia, tais vestígios encontram-se conservados por carbonização ou estão em associação com o material antracológico (Schell-Ybert 2004b).

Ao longo das pesquisas realizadas em sambaquis, compreender a dieta e os modos de subsistência destes povos manteve-se em primeiro plano (Bianchini et al. 2011). Entretanto, durante um longo período acreditou-se que essas sociedades eram usualmente limitadas à coleta de moluscos, à caça e à pesca (Bianchini et al. 2011). Atualmente, estudos mostram que suas ocupações eram estrategicamente posicionadas de forma a aproveitar áreas de interseção ecológica ricas em pescado, moluscos e recursos vegetais (Gaspar 1991, 1998, 2000; Scheel-Ybert et al. 2003). Apenas recentemente análises antracológicas demonstraram a importância dos vegetais para os homens do sambaqui e a relação deste grupo com o meio vegetal (ScheelYbert et al. 2003). Apesar disso, a presença do instrumento lítico denominado "quebra-coco" e a elevada ocorrência de vestígios do tipo "coquinhos" (carporrestos carbonizados) em sítios arqueológicos do litoral catarinense já se mostravam como fortes indícios do uso de recursos florestais pelos sambaquianos (Tiburtius 1996).

$\mathrm{Na}$ literatura atual são encontrados inúmeros relatos da presença de cocos carbonizados e preservados pelo processo de dessecamento no sedimento de sítios arqueológicos (Bandeira 2004; Scheel-Ybert 1998, 2001; Scheel-Ybert et al. 2003). Entretanto, são quase inexistentes os trabalhos que procuram identificar as espécies de tais recursos alimentares. Um dos raros registros restringe-se à presença de cocos carbonizados de jerivá (Syagrus romanzoffiana - Arecaceae) recuperados em sambaquis do litoral de Santa Catarina (Beck 1972).

Por outro lado, a condição climática tropical apresentada no Brasil o torna detentor de uma grande variedade de palmeiras (Arecaceae), sendo elas consideradas um dos grupos mais antigos do globo, cujos testemunhos fósseis datam de mais de 120 milhões de anos. Sua diversidade atual é representada por aproximadamente 2.600 espécies abrigadas em mais de 240 gêneros (Lorenzi et al. 2006). Destas, 297 espécies são nativas da flora brasileira, com cerca de 74 distribuídas na Mata Atlântica e trinta espécies restritas à porção sul do Brasil (Flora do Brasil 2015).

Cruzando os dados encontrados na literatura referente aos vestígios carbonizados presentes nos sítios arqueológicos e à riqueza de espécies de palmeiras presentes no Brasil, entende-se que pode haver uma significativa lacuna sobre a dieta alimentar do povo sambaquiano quanto ao uso deste recurso florestal. Sendo assim, este estudo objetivou identificar taxonomicamente os macrovestígios de origem vegetal (carporrestos carbonizados) de forma a ampliar os conhecimentos sobre a dieta alimentar sambaquiana. Foram hipóteses: (1) o jerivá não ocupava papel exclusivo no uso de palmeiras pelo homem do sambaqui; (2) a exclusividade do uso do jerivá relatada na literatura decorre de problemas tafonômicos; e (3) a exclusividade do uso do jerivá relatada na literatura está diretamente relacionada à falta de coleção de referência local para palmeiras. 


\section{Material e métodos}

Área de estudo e testemunhos vegetais

Todo o material arqueológico analisado é proveniente do sítio arqueológico Cubatão I e pertence ao acervo arqueológico do Museu de Sambaqui de Joinville. A quadra selecionada foi a N8W10, que compreende a trincheira N8 das quadras W03 à W14 (Fig. 1), escavadas entre os anos de 2008 e 2009. A seleção da quadra se deu em função da elevada presença de material vegetal carbonizado em matriz sedimentar composta por lentes de cinzas, carvões e frutos.

O sítio arqueológico Sambaqui Cubatão I está localizado na região nordeste do município de Joinville/SC, sob as coordenadas UTM: 7099808 N e 722575 E (Bandeira, Oliveira \& Santos 2009). O sítio pertence a um conjunto de sete sítios da embocadura do Rio Cubatão denominado, por Oliveira \& Horn Filho (2001), de Complexo Cubatão. Sua dimensão compreende aproximadamente $10 \mathrm{~m}$ de altura, $80 \mathrm{~m}$ de comprimento e $70 \mathrm{~m}$ de largura, de forma oval orientada no sentido norte-oeste/ sul-sudeste. É limitado ao norte por um declive abrupto tangenciado por um bosque de manguezal e encontra-se junto à foz do Rio Cubatão, na margem direita, que está sujeita a inundações periódicas (Gonçalves, Zanotelli \& Oliveira 2006). Prospecções no sítio indicam um sambaqui sem cerâmica ou vestígios de ocupações pré-coloniais (Bandeira 2004; Oliveira \& Horn Filho 2001).
A partir das primeiras intervenções realizadas no sítio em 2007, foram abertas oito sondagens e estabelecidas as áreas de escavação com 36 quadrículas de $1 \times 1 \mathrm{~m}$, com profundidade média de sessenta centímetros e estratigrafia artificial (Figuti 2009). Nas sondagens iniciais de escavação foram observadas apenas duas camadas, sendo uma constituída de sedimento argiloso marrom escuro, rico em matéria orgânica, sem conchas e com espessura entre dez e trinta centímetros; e outra camada caracterizada por coloração cinza, composta por fragmentos finos de conchas (Anomallocardia sp. e Mitela sp.) com bolsões e lentes de conchas inteiras de berbigão (Anomallocardia sp.) (Figuti 2009).

Estudo realizado na face nordeste do sítio que apresenta perfil exposto por erosão fluviomarinha permitiu compreender sua estratigrafia. Tal estratigrafia evidencia vinte camadas de distribuição irregular, compostas em sua maioria por sedimento arenoso (Bandeira, Oliveira \& Santos 2009). As camadas inferiores do sítio apresentaram, entre outros vestígios orgânicos, inúmeros artefatos de origem vegetal como: fibras trançadas (cordas e cestaria) (Peixe, Melo Júnior \& Bandeira 2007; Sá 2015) e estacas de madeira de diferentes espécies de manguezal e florestas de restinga, as quais teriam servido como base estrutural de sustentação do sítio (Melo Júnior, Silveira \& Bandeira 2016). Nos níveis superiores do sítio foram observadas camadas constituídas por carvões, cinzas e coquinhos (Bandeira, Oliveira \& Santos 2009). 

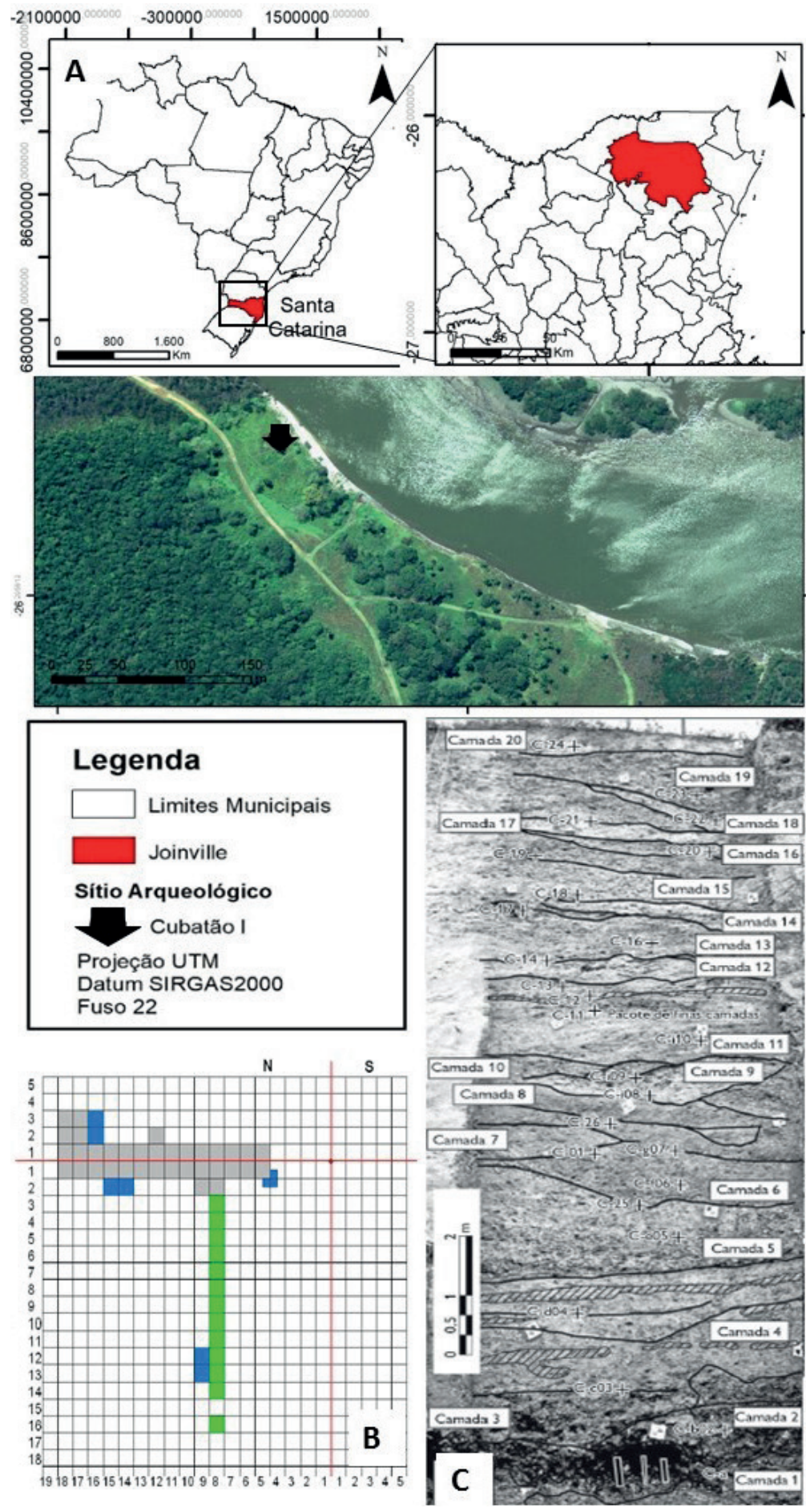

Fig. 1. Localização do sítio arqueológico Cubatão I, município de Joinville/SC. Perfil estratigráfico do sítio e croqui da área de escavação. Legenda: 1A - mapa indicando a localização, 1B - croqui das quadras escavadas (Figuti 2009), 1C - perfil estratigráfico do sítio.

Fonte: Bandeira, Oliveira \& Santos (2009). 
Coleção de referência e identificação taxonômica

Para a identificação taxonômica das espécies vegetais representadas pelos frutos carbonizados, seguiu-se a análise morfotipológica modificada de Rodrigues-Silva (2002). Após a classificação preliminar dos frutos por morfotipos, eles foram comparados com os frutos carbonizados da coleção carpológica de referência elaborada por Melo Júnior (2019).

Tal coleção de referência foi baseada na coleta de frutos de espécies de palmeiras nativas da flora brasileira, com ampla distribuição na Mata Atlântica stricto sensu e com ocorrência no litoral nordeste de Santa Catarina, contexto ambiental da existência de inúmeros sítios arqueológicos de tipologia sambaqui. A coleta e o tratamento do material carpológico seguiram as técnicas usuais em florística (Fidalgo \& Bononi 1989).

O material botânico foi herborizado, identificado e incorporado ao Herbário da Universidade da Região de Joinville (Herbário JOI).

A identificação das espécies foi baseada na literatura especializada, morfologia comparada e consulta a herbários. Para a confirmação dos nomes das espécies e dos respectivos autores foi utilizada a "Lista de espécies" da Flora do Brasil (2015). Testes tafonômicos foram realizados por meio da seleção de dez frutos in natura de cada espécie e com inteireza do pericarpo, os quais foram submetidos à combustão em forno tipo mufla nas temperaturas de $400^{\circ} \mathrm{C}$ e $600^{\circ} \mathrm{C}$ e nos tempos de trinta, 45 e sessenta minutos, método adaptado de Pearsall (2000). Dez frutos de cada espécie despolpados manualmente foram submetidos ao mesmo tratamento. Para compreensão do tempo de carbonização completa, os frutos que não carbonizaram ao período máximo de sessenta minutos foram submetidos a períodos maiores em mufla (máximo de seis horas). $\mathrm{O}$ registro fotográfico do material carbonizado foi obtido por meio de estereomicroscópio binocular Zeis. Todo o material foi incorporado à coleção antracológica de referência da Xiloteca JOI da Universidade da região de Joinville (Univille).

Desta coleção de referência, foram selecionadas seis espécies da família Arecaceae e com distribuição nos ecossistemas de entorno do sítio arqueológico estudado. São elas: Attalea dubia (Mart.) Burret, Bactris setosa Mart., Butia catarinensis Noblick \& Lorenzi, Euterpe edulis Mart., Geonoma schottiana Mart., Syagrus romanzoffiana (Cham.) Glassman. Por possuírem ampla distribuição na faixa costeira do estado de Santa Catarina, compreendendo as formações de Restinga e Floresta Ombrófila Densa stricto sensu (Lingner et al. 2013), tais espécies correspondem de forma imediata às espécies de palmeiras hipoteticamente disponíveis na área habitada no passado pela população sambaquiana. Após o processo de cura (triagem e identificação), os carporrestos foram quantificados e pesados em balança analítica de precisão a fim de obter, respectivamente, a ubiquidade e a massa total de frutos por nível estratigráfico.

\section{Determinação do valor nutricional}

De cada espécie de palmeira utilizada na confecção da coleção de referência, foram coletadas amostras no período fenológico de frutificação no total de um quilo de frutos, os quais foram acondicionados em saco plástico tipo zip e congelados a $-5^{\circ} \mathrm{C}$. Tais frutos foram destinados à análise química no Laboratório de Nutrição Animal, da Universidade Federal do Paraná (UFPR), para a determinação do seu teor nutricional, considerando: cálcio, fósforo, proteína bruta, lipídios, carboidratos, fibra bruta, umidade e cinzas.

\section{Resultados}

Ao total, foram analisados 905 macrovestígios vegetais $(261 \mathrm{~g})$ tipificados como carporrestos carbonizados. Destes, sessenta carporrestos (ca. 7\%) não foram passíveis de análise, em razão do seu tamanho reduzido e/ou alta friabilidade. O perfil carpológico obtido mostrou a distribuição dos carporrestos em diferentes níveis estratigráficos da matriz arqueológica, com maior prevalência na camada localizada à profundidade de 2,03-2,08 m (Fig. 2) . 
Foram identificadas taxonomicamente três espécies de frutos/sementes pertencentes a duas famílias botânicas: Euterpe edulis Mart., Syagrus romanzoffiana (Cham.) Glassman. (Arecaceae) e Vantanea compacta (Schnizl.) Cuatrec. (Humiriaceae) (Fig. 3). Aproximadamente 36\% dos carporrestos correspondem à espécie E. edulis (327 fragmentos), $31 \%$ à espécie $V$. compacta (285 fragmentos) e $26 \%$ à espécie S. romanzoffiana (233 fragmentos).

A prevalência dos carporrestos de palmeiras (62\%) é também registrada ao longo dos níveis estratigráficos da matriz arqueológica (Figura 2).

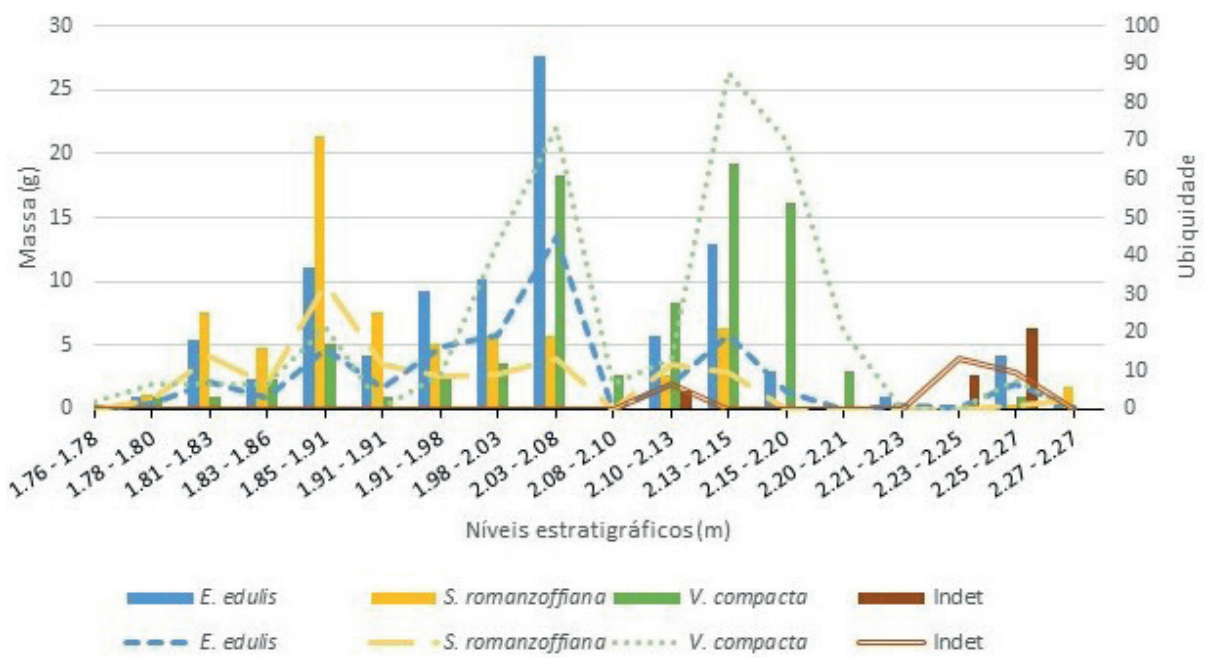

Fig. 2. Perfil carpológico da quadra N8W10 do sítio arqueológico Cubatão I, município de Joinville/SC. Legenda: barras contínuas e linhas pontilhadas compreendem, respectivamente, a massa e a ubiquidade dos vestígios carpológicos.
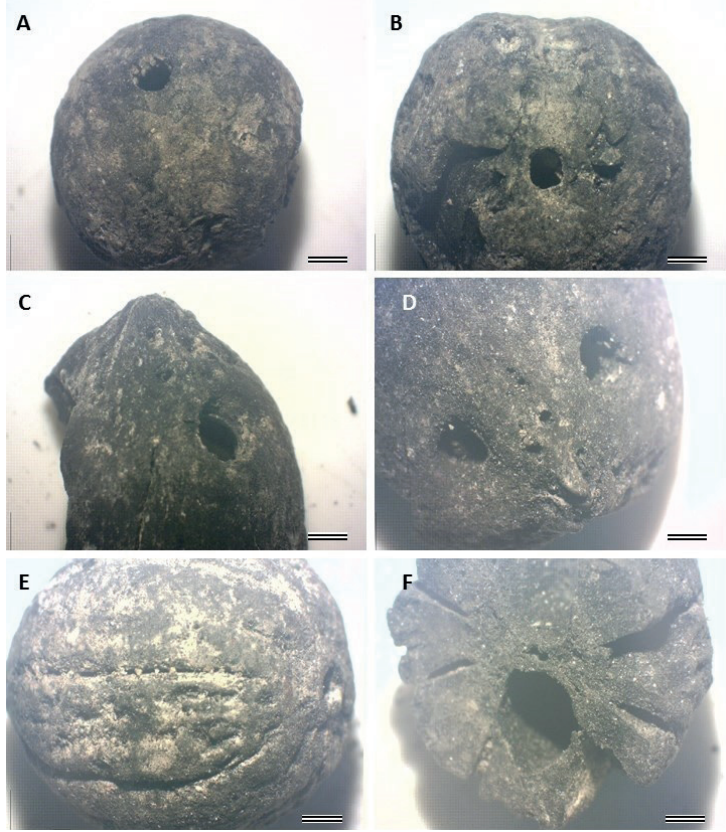

Fig. 3. Carporrestos carbonizados identificados do sítio arqueológico Cubatão I, município de Joinville/SC. Legenda: 3A e 3B - Semente de Euterpe edulis (Arecaceae) 3C e 3D - Syagrus romanzoffiana (Arecaceae); 3E e 3F fruto de Vantanea compacta (Humiriaceae). Barra de escala $=1 \mathrm{~mm}$. 


\section{Discussão}

Apesar do sugestivo predomínio neste estudo de frutos de palmeiras, alguns autores destacam a importância de compreender quantitativamente a disponibilidade destes recursos (frutos e sementes) no ambiente, de maneira a compreender a sua representatividade no sedimento arqueológico, levando em consideração a relação direta da presença destes recursos no sítio e das particularidades biológicas inerentes à espécie vegetal (Nakamura, Melo Júnior \& Ceccantini 2010). De maneira complementar, o conhecimento da fenologia, da taxa de produção de frutos/ sementes e de seu rendimento energético auxilia no entendimento de como as populações pretéritas poderiam utilizar esses recursos, assim como as estratégias associadas, tais quais a coleta seletiva ou fortuita de recursos. Naturalmente, espera-se representatividade maior de vestígios num sítio arqueológico se uma determinada espécie apresentar características como: maior produção de frutos, elevada abundância, facilidade de acesso para a coleta e elevada resistência dos frutos/ sementes à deterioração, como é evidenciado nos coquinhos (Nakamura, Melo Júnior \& Ceccantini 2010). Dentre algumas espécies de palmeiras da Mata Atlântica, a Euterpe edulis e Syagrus romanzoffiana se destacam por apresentar abundância e elevada distribuição geográfica (Lingner et al. 2013).

A presença deste tipo de carporrestos (Arecaceae) em sítios arqueológicos é evidente, mas poucos buscam compreender sua relação com a dieta de populações passadas ou identificá-la com o menor nível taxonômico (Gussella 2003). Nesta perspectiva, o registro sugerindo o consumo exclusivo dos frutos de jerivá (Syagrus romanzoffiana) (Beck 1972) evidencia uma importante lacuna sobre o modo de vida dos sambaquianos, seus hábitos alimentares e suas relações de uso dos recursos florestais. Entretanto, a confirmação da presença dos coquinhos de Euterpe edulis, preservados pelo processo de carbonização, amplia o conhecimento sobre o consumo deste recurso por populações pretéritas.

Além disto, o registro de uma nova espécie (Vantanea compacta - Humiriaceae) no contexto da dieta alimentar dos sambaquis corrobora este cenário. Em pesquisa desenvolvida com vestígios carpológicos utilizados por grupos pretéritos que ocuparam o Brasil Central, Gussella (2003) relata a presença de frutos do gênero Humiria A. St.-Hil. (Humiriaceae). A presença destes vestígios, em associação às fogueiras em sítios arqueológicos do Brasil, vai ao encontro do que é relatado em literatura para o consumo e práticas de subsistência de populações tradicionais atuais que envolvem espécies frutíferas da família Humiriaceae (Lorenzi 2010; Magalhães et al. 2007).

Apesar do crescente número de pesquisas arqueobotânicas, os trabalhos ainda são incipientes e não respondem todas as lacunas existentes, de maneira que as inferências sobre a possível predileção e/ou consumo de recursos vegetais por populações pretéritas muitas vezes apoia-se em literatura etnográfica e/ou por aproximação às comunidades tradicionais atuais (Nakamura, Melo Júnior \& Ceccantini 2010). Conhecidamente, as palmeiras detêm grande potencial econômico e são empregadas em diversas atividades de interesse econômico em diferentes regiões do Brasil (Claudino \& Soares 2013). Diferentes espécies têm seus frutos, assim como o caule e as folhas, empregados no preparo de insumos para atividades ritualísticas ou servem de matériaprima para a subsistência de diferentes povos indigenas, comunidades quilombolas, entre outros grupos tradicionais ainda hoje existentes (Amaral 2010; Barroso, Reis \& Hanazaki 2010; Cruz 2010; Oliveira et al. 2014).

Conforme supracitado, o emprego e a utilização dos recursos oriundos das palmeiras por populações tradicionais atuais são recorrentes na literatura etnográfica brasileira, e é seguro afirmar que tais conhecimentos acabam por direcionar alguns grupos quanto à escolha de algumas espécies para finalidades específicas, incluindo o uso alimentar. Entretanto, conhecer a atual diversidade deste conjunto de espécies vegetais (família Arecaceae) 
ajuda a compreender de forma indireta e aproximada a vegetação pretérita existente no entorno dos locais de habitação de sociedades extintas.

A coleta seletiva tem sido um modo de subsistência extrativista reportado em pesquisas arqueobotânicas e/ou paleoetnobotânicas realizadas em sítios arqueológicos do Brasil. Em estudo com grânulos de amido e fitólitos em cálculos dentários humanos de grupos pretéritos do litoral norte do estado de Santa Catarina, Wesolowski (2007) ampliou o conhecimento com relação ao consumo seletivo de alguns recursos de origem vegetal. Posteriormente, Wesolowski e colaboradores (2007) sugerem, com base na variação dos conjuntos de grânulos de amido e fitólitos pertencentes a distintas espécies e famílias botânicas, a seleção diferenciada dos recursos utilizados a partir do espectro de disponibilidade deles, implicando possíveis padrões de escolha dos grupos humanos com base na variação local, temporal e sazonal das espécies.

De forma análoga, o que foi demonstrado por Melo Júnior \& Magalhães (2015), ao correlacionar os dados a respeito das propriedades físico-químicas da madeira juntamente com a assembleia de carvões recuperados em sítio arqueológico do tipo abrigo sob rocha no Brasil Central, atestam uma importante relação entre o poder calorífico de espécies lenhosas e a coleta seletiva de madeiras utilizadas em estruturas de combustão por populações pretéritas. Neste sentido, outros trabalhos paleoetnobotânicos com macrovestígios vegetais não carbonizados relacionam o emprego de diferentes "instrumentos" a um viés seletivo na manipulação de plantas, tendo em vista seus usos do ponto de vista tecnológico (Ceccantini \& Gussella 2001; Peixe, Melo Júnior \& Bandeira 2007).

Em pesquisa realizada no sítio arqueológico Lapa das Boleiras, no interior de Minas Gerais, Nakamura, Melo Júnior e Ceccantini (2010) concluem que os frutos mais importantes enquanto recurso alimentar são os coquinhos. Os autores sugerem que estes desempenhavam importante papel tanto na alimentação quanto como combustivel para as estruturas de combustão, em função do elevado teor oleaginoso e da rigidez do endocarpo. $\mathrm{O}$ mesmo é relatado por Scheel-Ybert (2001) em ocupações litorâneas do sul do Brasil, onde há forte presença de fragmentos de frutos de palmeiras associados a fogueiras e preservados pelo processo de carbonização e/ou dessecamento. A autora sugere que estes coquinhos (sementes) poderiam ser descartados nas fogueiras após o consumo da parte externa e carnosa do fruto (parte do pericarpo).

Apesar dos frutos de palmeira, de forma geral, terem sido mais representativos, analisando-os separadamente fica claro que a espécie S. romanzoffiana não foi a mais expressiva ao longo do perfil carpológico obtido para este estudo, tendo em vista a prevalência dos frutos de E. edulis, com maior ubiquidade ao longo dos níveis estratigráficos e seguida dos frutos de $V$. compacta. Sugestivamente, pode-se inferir que a baixa representatividade da espécie S. romanzoffiana possa estar relacionada a períodos prolongados de exposição a fogueiras, uma vez que seus frutos apresentaram elevado grau de fragmentação, de maneira que nenhuma semente inteira foi observada na quadra estudada, diferindo das demais espécies identificadas. Além disso, o registro de instrumentos líticos (quebra-cocos) destinados à maceração de vegetais é recorrente em sítios arqueológicos no Brasil (Pugliese 2007; Tiburtius 1996). Tendo em vista que parte do endocarpo do fruto de algumas espécies de palmeiras pode ser muito rígida, podendo ser equiparada ao lenho de elevada densidade de espécies arbóreas (Nakamura, Melo Júnior \& Ceccantini 2010), estes dados suportariam as altas taxas de fragmentação para os "coquinhos" de algumas espécies de palmeiras, como observado para os vestígios da espécie $S$. romanzoffiana nesta pesquisa, entre outras relatadas em diferentes sítios arqueológicos do Brasil.

Nakamura, Melo Júnior \& Ceccantini (2010) também relatam a excessiva friabilidade por parte dos vestígios de uma espécie aparentada (Syagrus flexuosa (Mart.) Becc.). Conforme Melo Júnior (2019), os testes 
tafonômicos experimentais com a espécie S. romanzoffiana demonstraram baixa friabilidade mesmo após combustão a $600^{\circ} \mathrm{C}$, mas o autor destaca que processos pós-deposicionais implicam a possivel fragmentação dos vestígios obtidos de sítios arqueológicos. Pesquisas relacionadas sustentam que, em condições deposicionais naturais, as características particulares de cada espécie, aliadas às influências ambientais como processos de bioturbação causados por raízes ou animais, podem influenciar no processo de fragmentação dos macrovestígios carbonizados (Santana \& Carvalho 2013; Scheel-Ybert 2003;

Théry-Parisot, Chabal \& Chrzavzez 2010).

Elias e colaboradores (2016), por meio do Inventário Florístico Florestal de Santa Catarina, destacam as espécies Euterpe edulis e Syagrus romanzoffiana como sendo as palmeiras mais abundantes e com maior distribuição geográfica, respectivamente. A E. edulis apresenta maior densidade, com 35,84 indivíduos por ha ${ }^{-1}$, bem como maior frequência, ocorrendo em 54\% das unidades amostrais alocadas na Floresta Pluvial do estado. Já a espécie S. romanzoffiana apresentou maior dominância $\left(486.62 \mathrm{~m}^{2} \cdot \mathrm{ha}^{-1}\right)$, ocorrendo em todas a formações vegetais do estado (Elias et al. 2016). A ampla disponibilidade de frutos de palmeiras associada ao poder calorifico deste recurso, geralmente presentes em estruturas de combustão (fogueiras) ou preservados pelo processo de carbonização, sugerem uma coleta seletiva.

Com base nos valores nutricionais obtidos para as espécies dos carporrestos de palmeiras identificados na quadra analisada, nota-se a prevalência em termos energéticos dos frutos de E. edulis, tendo em vista que os valores de lipídios $(4,35 \%)$, proteínas $(6,60 \%)$ e carboidratos $(84,75 \%)$ foram superiores, quando comparados à espécie S. romanzoffiana (Tabela 1). Ainda assim, os frutos de palmeiras de maneira geral são extremamente nutritivos e ricos em óleo (Martins et al. 2015).

Tais características, associadas à elevada abundância e à ampla distribuição geográfica apresentada por E. edulis em formações florestais da Mata Atlântica sobre a planície costeira de Santa Catarina, corroboram a hipótese da coleta seletiva desse recurso.

\begin{tabular}{lcccccccc}
\hline \multicolumn{1}{c}{ Espécie } & \multicolumn{7}{c}{ Valores nutricionais (\%) } \\
\hline Attalea dubia & $\mathrm{Ca}$ & $\mathrm{P}$ & $\mathrm{PB}$ & $\mathrm{LP}$ & $\mathrm{CB}$ & $\mathrm{FB}$ & $\mathrm{UM}$ & $\mathrm{CI}$ \\
Bactris setosa & 0,16 & 0,17 & 7,3 & 12,3 & 65,34 & 32,2 & 62,70 & 1,78 \\
Butia catarinensis & 0,15 & 0,12 & 6,42 & 7,12 & 69,24 & 35,93 & 61,60 & 2,11 \\
Euterpe edulis & 0,14 & 0,16 & 6,51 & 14,39 & 54,20 & 31,94 & 22,96 & 2,12 \\
Geonoma schottiana & 0,25 & 0,19 & 6,60 & 4,35 & 84,75 & 51,17 & 53,36 & 2,64 \\
Syagrus romanzoffina & 0,26 & 0,17 & 10,56 & 10,02 & 74,21 & 36,54 & 48,63 & 4,19 \\
\hline
\end{tabular}

Tabela 1: Valores nutricionais das espécies de frutos de palmeiras com base na coleção de referência para a Mata Atlântica stricto sensu, Joinville/SC, Brasil. Legenda: Ca (cálcio), P (fósforo), PB (proteína bruta), LP (lipídios), CB (carboidratos), FB (fibra bruta), UM (umidade) e CI (cinzas).

Muitos representantes da família Arecaceae possuem frutificação abundante, não se restringindo à sazonalidade definida (Lorenzi et al. 2006). A E. edulis pode produzir em média 2.175 frutos por infrutescência em um período fenológico que vai de março a dezembro (Silva \& Reis 2018). A espécie S. romanzoffiana pode apresentar até duas florações anuais em dois eventos bem definidos temporalmente, cuja produção de frutos pode chegar a oitocentas unidades por cacho, apresentando longos períodos para maturação (Begnini, Silva \& Castellani 2013; Galetti, Paschoal \& Pedroni 1992). Desta forma, a ampla oferta de frutos 
de elevado valor nutricional ao longo de um mesmo ano pode ser entendida como uma significativa fonte de recursos alimentares a ser forrageada. Embora não haja informações disponíveis sobre o seu conteúdo nutricional, os frutos de V. compacta assemelham-se aos frutos de uxi (Endopleura uchi (Huber) Cuatrec), ambas espécies pertencentes à família Humiriaceae e consumidas atualmente por populações tradicionais. Tal espécie tem seu valor nutricional conhecido, sendo constituído de: proteínas $(1,20 \mathrm{~g})$, lipídios $(20,2 \mathrm{~g})$ e carboidratos $(30,6 \mathrm{~g})$ para cada cem gramas de fruto (Lorenzi et al. 2006). Com relação à fenologia de $V$. compacta, a espécie produz anualmente abundante quantidade de frutos, com o amadurecimento em junho/agosto (Lorenzi 2002).

\section{Conclusão}

Os resultados obtidos neste trabalho mostram que: o jerivá não ocupava papel exclusivo no uso de palmeiras pelo homem do sambaqui, tendo em vista o registro de duas novas espécies identificadas na matriz sedimentar do sítio estudado; a exclusividade do uso do jerivá relatada na literatura decorre de problemas tafonômicos e, por vezes, da ausência de coleções de referência com base na flora local para análises comparativas mais fiáveis. Contudo, as identificações taxonômicas realizadas ampliam o espectro de recursos florestais utilizados pelos sambaquianos no litoral de Santa Catarina, seu conhecimento sobre as espécies vegetais e o entendimento sobre o modo de vida e a dieta alimentar de populações pretéritas.

OLIVEIRA, G.B.; MELO JÚNIOR, J.C.F. New archaeobotanical records about the use of fruits in sambaqui diet. R. Museu Arq. Etn. 34: 174-186, 2020.

\begin{abstract}
For archaeological sites in Brazil, there are countless reports of the presence of carbonized fruits (coquinhos) in sambaquis. However, difficulties in identifying associated species caused by the megadiverse scenario of the Brazilian flora has resulted in scarce knowledge on the diet of sambaqui people. This study taxonomically identified the macrobotanical remains of carbonized fruits in order to better understand the diet of sambaqui people. All archaeological material analyzed came from the Cubatão I archaeological site in the municipality of Joinville/SC, and belongs to the archaeological collection of the Sambaqui Museum of Joinville. The taxonomic identification of plant species (carbonized fruits) was based on classifying the fruits into morphotypes and then comparing them with a reference carpological collection belonging to the Laboratory of Plant Morphology and Ecology of Univille University. Samples of ripe fruits from palms were collected to determine their nutritional content. A total of 905 macrobotanical remains (261 g) typified as carbonized fruits were analyzed. The resulting carpological profile showed the highest prevalence in the layer located at a depth of 2.03-2.08 m. Three fruit/seed species belonging to two botanical families were identified: juçara palm - Euterpe edulis Mart., jerivá - Syagrusromanzoffiana (Cham.) Glassman (Arecaceae) and guaraparim Vantanea compacta (Schnizl.) Cuatrec. (Humiriaceae). The taxonomic identifications made during this study increase what is known about the range of forest resources used by the sambaqui on the coast of Santa Catarina, their knowledge on plant species, and the way of life and the diet of past populations.
\end{abstract}

Keywords: Cultural heritage; archaeobotany; anthracology; carpology; sambaquis. 
Novos registros arqueobotânicos sobre o uso de frutos na dieta alimentar sambaquiana

R. Museu Arq. Etn., 34: 174-186, 2020.

\section{Referências bibliográficas}

Amaral, A.J.P. 2010. Artesanato quilombola: identidade e etnicidade na Amazônia. Cadernos do CEOM 23(32): 61-75.

Bandeira, D.R. 2004. Ceramistas pré-coloniais da Baía da Babitonga, SC: arqueologia e etnicidade. Tese de doutorado. Universidade Estadual de Campinas, Campinas.

Bandeira, D.R.; Oliveira, E.L.; Santos, A.M.P. 2009. Estudo estratigráfico do perfil nordeste do Sambaqui Cubatão I, Joinville/SC. Revista do Museu de Arqueologia e Etnologia 19: 119-142.

Barroso, R.M.; Reis, A.; Hanazaki, N. 2010. Etnoecologia e etnobotânica da palmeira juçara (Euterpe edulis Martius) em comunidades quilombolas do Vale do Ribeira, São Paulo. Acta Botânica Brasílica 24(2): 518-528.

Beck, A.M. 1972. A variação do conteúdo cultural dos sambaquis: litoral de Santa Catarina. Tese de doutorado. Universidade de São Paulo, São Paulo.

Begnini, R.M.; Silva, F.R.; Castellani, T.T. 2013. Fenologia reprodutiva de Syagrus romanzoffiana (Cham.) Glassman (Arecaceae) em Floresta Atlântica no sul do Brasil. Biotemas 26(4): 53-60.

Bianchini, G.F. et al. 2011. Processos de formação do sambaqui Jabuticabeira-II: interpretações através da análise estratigráfica de vestígios vegetais carbonizados. Revista de Museu de Arqueologia e Etnologia 21: 51-69.

Ceccantini, G.C.T.; Gussella, L.W. 2001. Os novelos de fibras do abrigo rupestre Santa Elina (Jangada, MT, Brasil): anatomia vegetal e paleoetnobotânica. Revista do Museu de Arqueologia e Etnologia 11: 189-200.

Chabal, L. 1997. Forêts et sociétés en Languedoc (Néolithique final, Antiquité tardive): Lanthracologie, méthode et paléoécologie. Editions MSH, Paris.
Chabal, L. et al. 1999. L'anthracologie. In: BourquinMignot, C. et al. (Eds.). La botanique. Ed. Errance, Paris, 105-137.

Claudino, W.V.; Soares, C.R.A. 2013. Levantamento fitossociológico de palmeiras presentes no Parque Nacional do Juruena, sítio do PPBio. In: Anais da 5a Jornada Científica da Unemat, 2013, Cáceres.

Clement, C.R.; Pérez, E.L.; Van Leeuwen, S.J. 2005. O potencial das palmeiras tropicais no Brasil: acertos e fracassos das últimas décadas. Agrociencia 9(1): 67-71.

Coimbra, M.C.; Jorge, N. 2011. Proximate composition of guariroba (Syagrus oleracea), jerivá (Syagrus romanzoffiana) and macaúba (Acrocomia aculeata) palm fruits. Food Research International 44(7): 2139-2142.

Cruz, T.A. 2010. Mulheres da floresta do vale do Guaporé e suas interações com o meio ambiente. Revista Estudos Feministas 18(3): 913-925.

Elias, G.A. et al. 2016. Community structure of large native arborescent palms (Arecaceae) using data from the floristic and forest Inventory of Santa Catarina, Brazil. Australian Journal of Basic and Applied Sciences 10(10): 156-163.

Fidalgo, O.; Bononi, V.L.R. 1989. Técnicas de coleta, preservação e herborização de material botânico. Imprensa Oficial, São Paulo.

Figueiral, I.; Mosbrugger, V. 2000. A review of charcoal analysis as a tool for assessing Quaternary and Tertiary environments: achievements and limits. Palaeogeography, Palaeoclimatology, Palaeoecology 64(1-4): 397-407.

Figuti, L. 2009. Construindo o sambaqui: a ocupação e os processos de construção de sítio na bacia do Canal do Palmital, Santa Catarina. Relatório final de capacitação técnica. Fapesp, 08/01285-0, São Paulo. 
Flora do Brasil. 2015. Arecaceae Schultz Sch. Disponível em: https://bit.ly/2uuiJNf. Acesso em: 19 nov. 2018.

Galetti, M.; Paschoal; M.; Pedroni, F. 1992. Predation on palms nuts (Syagrus romanzoffiana) by squirrels (Sciurus ingrami) in south-east Brazil. Journal of Tropical Ecology 8(1): 121-123.

Gaspar, M.D. 1991. Aspectos da organização de um grupo de pescadores, coletores e caçadores: região compreendida entre a Ilha Grande e o delta do Paraíba do Sul, estado do Rio de Janeiro. Tese de doutorado. Universidade de São Paulo, São Paulo.

Gaspar, M.D. 1998. Considerations of the sambaquis of the Brazilian coast. Antiquity 72(277): 592-615.

Gaspar, M. 2000. Sambaqui: arqueologia do litoral brasileiro. Jorge Zahar, Rio de Janeiro.

Gonçalves, M.L.; Zanotelli, C.T.; Oliveira, F.A. 2006. Diagnóstico e prognóstico das disponibilidades e demandas hídricas do rio Cubatão do NorteJoinville - Santa Catarina. Ed. Univille, Joinville.

Gussella, L.W. 2003. Identificação de restos vegetais do sítio arqueológico Santa Elina - MT. Trabalho de conclusão de curso. Universidade Federal do Paraná, Curitiba.

Lingner, D.V. et al. 2013. Fitossociologia do componente arbóreo/arbustivo da floresta ombrófila densa em Santa Catarina. In: Vibrans, A.C. et al. (Eds.). Inventário florístico florestal de Santa Catarina. Edifurb, Blumenau, 160-200.

Lorenzi, H. 2002. Árvores brasileiras: manual de identificação e cultivo de plantas arbóreas do Brasil. Plantarum, São Paulo.

Lorenzi, H. 2010. Flora brasileira: Arecaceae (palmeiras). Plantarum, São Paulo.

Lorenzi, H. et al. 2006. Frutas brasileiras e exóticas cultivadas (de consumo in natura). Plantarum, São Paulo.
Magalhães, L.A. et al. 2007. Identificação de bergenina e carotenóides no fruto de uchi (Endopleura uchi, Humiriaceae). Acta Amazonica 37(3): 447-450.

Martins, V. et al. 2015. Caracterização química da polpa do fruto jerivá (Syagrus romanzoffiana Cham.). Revista Virtual de Química 7(6): 2422-2437.

Melo Júnior, J.C.F. 2019. Anthracological reference collection of palms of the Atlantic Forest (sensu stricto) of southern Brazil. International Journal for Innovation Education and Research 7(2): 238-253.

Melo Júnior, J.C.F.; Magalhães, W.L.E. 2015. Antracologia de fogueiras paleoíndias do Brasil Central: considerações tecnológicas e paleoetnobotânicas sobre o uso de recursos florestais no abrigo rupestre Lapa do Santo, Minas Gerais, Brasil. Antípoda 22: 137-161.

Melo Júnior, J.C.F.; Silveira, E.R.; Bandeira, D.R. 2016. Arqueobotânica de um sambaqui sul-brasileiro: integrando indícios sobre o paleoambiente e o uso de recursos florestais. Boletim do Museu Paraense Emílio Goeldi Ciências Humanas 11(3): 727-744.

Nakamura, C.; Melo Júnior, J.C.F.; Ceccantini, G. 2010. Macro-restos vegetais: uma abordagem paleoetnobotânica e paleoambiental. In: Araújo, A.G.M.; Neves, W.A. (Orgs.). Lapa das Boleiras: um sítio paleoíndio do carste de Lagoa Santa, MG, Brasil. Annablume, São Paulo, 158-177.

Oliveira, M.S.C.; Horn Filho, N.O. 2001. De Guaratuba a Babitonga: uma contribuição geológico-evolutiva ao estudo da espacialidade dos sambaquianos no litoral norte catarinense. Revista do Museu de Arqueologia e Etnologia 11: 55-75.

Oliveira, M.S.C. 2000. Os sambaquis da planície costeira de Joinville, litoral norte de Santa Catarina: Geologia, Paleografia e conservação in situ. Dissertação de mestrado. Universidade Federal de Santa Catarina, Florianópolis.

Oliveira, O.M. et al. 2014. Espécies botânicas utilizadas no artesanato comercializado na cidade de Altamira-PA. Biota Amazônia 4(4): 1-5. 
Novos registros arqueobotânicos sobre o uso de frutos na dieta alimentar sambaquiana

R. Museu Arq. Etn., 34: 174-186, 2020.

Pearsall, D.M. 2000. Paleoethnobotany: a handbook of procedures. Florida Academic Press, Orlando.

Peixe, S.P.; Melo Júnior, J.C.F.; Bandeira, D.R. 2007. Paleoetnobotânica dos macrorestos vegetais do tipo trançados de fibras encontrados no sambaqui Cubatão I, Joinville-SC. Revista do Museu de Arqueologia e Etnologia 17: 211-222.

Pugliese, F.A. 2007. Os líticos de Lagoa Santa: um estudo sobre a organização tecnológica de caçadorescoletores do Brasil central. Dissertação de mestrado. Universidade de São Paulo, São Paulo.

Rodrigues-Silva, D.G. 2002. Análise dos vestígios botânicos do início do Holoceno (10.000-8.000AP) no sítio arqueológico Lapa do Santo, APA carste de Lagoa Santa, Minas Gerais. Trabalho de conclusão de curso. Universidade de São Paulo, São Paulo.

Sá, J.C. 2015. Etnoarqueologia e Arqueologia experimental: desatando informações sobre nós e amarrações em fibras do sambaqui Cubatão I, em Joinville - SC. Monografia. Universidade da Região de Joinville, Joinville.

Santana, E.A.; Carvalho, O.A. 2013. Fraturas nos ossos: violência, acidente ou bioturbação? Laboratório de Antropologia e Arqueologia, Pelotas 10(20): 131-157.

Scheel-Ybert, R. 1998. Stabilité de l'ecosysteme sur le littoral sud-est du Brésil à l'holocene superieur (5500-1400 ans BP) : les pêcheurs-cueilleurschasseurs et le milieu végétal: apports de l'Anthracologie. Thèse de doctorat. Université Montpellier II, Montpellier.

Scheel-Ybert, R. 2001. Man and vegetation in the Southeastern Brazil during the late Holocene. Journal of Archaelogical Science 28: 471-480.

Scheel-Ybert, R. 2003. Importância da análise de macro-restos vegetais para a reconstituição do modo de vida de populações pré-históricas.
In: Anais do $12^{\circ}$ Congresso da Sociedade de Arqueologia Brasileira, 2003, São Paulo.

Scheel-Ybert, R. 2004a. Teoria e métodos em antracologia: técnicas de campo e de laboratório. Arquivos do Museu Nacional 62(4): 343-356.

Scheel-Ybert, R. 2004b. Teoria e métodos em antracologia: considerações teóricas e perspectivas. Arquivos do Museu Nacional 62(1): 3-14.

Scheel-Ybert, R. et al. 2003. Novas perspectivas na reconstituição do modo de vida dos sambaquieiros: uma abordagem multidisciplinar. Revista Arqueologia 16: 109-137.

Silva, J.Z.; Reis, M.S. 2018. Fenologia reprodutiva e produção de frutos em Euterpe edulis (Martius). Ciência Florestal 28(1): 295-309.

Théry-Parisot, I.; Chabal, L.; Chrzavzez, J. 2010. Anthracology and taphonomy, from wood gathering to charcoal analysis: a review of the taphonomic processes modifying charcoal assemblages, in archaeological contexts. Palaeogeography, Palaeoclimatology, Palaeoecology 291(1-2): 142-153.

Tiburtius, G. 1996. Arquivos de Guilherme Tiburtius. Museu Arqueológico de Sambaqui de Joinville, Joinville.

Wesolowski, V. 2007. Cáries, desgaste, cálculos dentários e micro-resíduos da dieta entre grupos pré-históricos do litoral norte de Santa Catarina: é possível comer amido e não ter cárie? Tese de doutorado. Escola Nacional de Saúde Pública Sérgio Arouca, Fiocruz, Rio de Janeiro.

Wesolowski, V. et al. 2007. Grânulos de amido e fitólitos em cálculos dentários humanos: contribuição ao estudo do modo de vida e subsistência de grupos sambaquianos do litoral sul do Brasil. Revista do Museu de Arqueologia e Etnologia 17: 191-210. 